\title{
Determination of Residual Nonsteroidal Anti-Inflammatory Drugs in Aqueous Sample Using Magnetic Nanoparticles Modified with Cetyltrimethylammonium Bromide by High Performance Liquid Chromatography
}

\author{
Malihe Khoeini Sharifabadi, ${ }^{1}$ Mohammad Saber-Tehrani,, Syed Waqif Husain, ${ }^{1}$ \\ Ali Mehdinia, ${ }^{2}$ and Parviz Aberoomand-Azar ${ }^{1}$ \\ ${ }^{1}$ Department of Chemistry, Science and Research Branch, Islamic Azad University, Poonak Hesarak, Tehran, Iran \\ ${ }^{2}$ Department of Marine Science, Iranian National Institute for Oceanography, Tehran, Iran
}

Correspondence should be addressed to Syed Waqif Husain; syedwaqifhusain@yahoo.com

Received 29 November 2013; Accepted 12 February 2014; Published 1 June 2014

Academic Editors: M. Edery and S. Wei

Copyright (C) 2014 Malihe Khoeini Sharifabadi et al. This is an open access article distributed under the Creative Commons Attribution License, which permits unrestricted use, distribution, and reproduction in any medium, provided the original work is properly cited.

\begin{abstract}
A simple and sensitive solid-phase extraction method for separation and preconcentration of trace amount of four nonsteroidal anti-inflammatory drugs (naproxen, indomethacin, diclofenac, and ibuprofen) using $\mathrm{Fe}_{3} \mathrm{O}_{4}$ magnetic nanoparticles modified with cetyltrimethylammonium bromide has been developed. For this purpose, the surface of $\mathrm{MNP}_{\mathrm{s}}$ was modified with cetyltrimethylammonium bromide $(\mathrm{CTAB})$ as a cationic surfactant. Effects of different parameters influencing the extraction efficiency of drugs including the $\mathrm{pH}$, amount of salt, shaking time, eluent type, the volume of solvent, amount of adsorbent, sample volume, and the time of desorption were investigated and optimized. Methanol has been used as desorption solvent and the extracts were analysed on a reversed-phase octadecyl silica column using $0.02 \mathrm{M}$ phosphate-buffer $(\mathrm{pH}=6.02)$ acetonitrile $(65: 35 \mathrm{v} / \mathrm{v})$ as the mobile phase and the effluents were measured at $202 \mathrm{~nm}$ with ultraviolet detector. The relative standard deviation (RSD\%) of the method was investigated at three concentrations $(25,50$, and $200 \mathrm{ng} / \mathrm{mL})$ and was in the range of $3.98-9.83 \%(n=6)$ for $50 \mathrm{ng} / \mathrm{mL}$. The calibration curves obtained for studied drugs show reasonable linearity $\left(R^{2}>0.99\right)$ and the limit of detection $\left(\operatorname{LOD}_{\mathrm{s}}\right)$ ranged between 2 and $7 \mathrm{ng} / \mathrm{mL}$. Finally, the proposed method has been effectively employed in extraction and determination of the drugs in biological and environmental samples.
\end{abstract}

\section{Introduction}

Nonsteroidal anti-inflammatory drugs $\left(\right.$ NSAID $\left._{\mathrm{S}}\right)$ with analgesic and antipyretic properties are used as the first-choice agents in the treatment of the allergies and reducing pain in human and veterinary medicine [1]. Recently some NSAID $_{S}$ have been used in cancer chemotherapy and chemoprevention. In addition to the antitumor activity of $\mathrm{NSAID}_{\mathrm{S}}$ as single agents, there is interest in the effects of combination chemotherapy with $\mathrm{NSAID}_{S}$ [2]. A review of the literature shows that naproxen, indomethacin, sodium diclofenac, and ibuprofen are often the acidic drugs $(\mathrm{pKa}=4.2, \mathrm{pKa}=$ $4.5, \mathrm{pKa}=4.2$, and $\mathrm{pKa}=5.2$ ) and the residues of these compounds can enter the environment from different ways: during their manufacture, during the disposal of unused or expired drugs, and through human and animal excretions $[3,4]$. Although the concentrations of these drugs are relatively low in water $\left(\mathrm{ngL}^{-1}\right.$ to $\left.\mu \mathrm{gL}^{-1}\right)$, continuous release and chronic exposure to these substances, because of their toxicity, can affect the intestinal, hematopoietic, and renal systems which can be a harmful to human health [5]. Therefore, development of a simple and robust method for the determination of these drugs in urine and wastewater is necessary for toxicological and therapeutic purposes. Because of their low concentration in complex matrix, different methods are used to separate and preconcentrate the analyte 
prior to its determination. Different combined methods have been reported for the determination of $\mathrm{NSAID}_{\mathrm{S}}$ such as solid phase microextraction-high performance liquid chromatography (SPME-HPLC) [6], solid phase extraction-liquid chromatography (SPE-LC) [7, 8], solid phase extractiongas chromatography-tandem mass (SPE-GC-MS/MS) [9], hollow fiber liquid phase microextraction (HFLPME)-HPLC [10], and molecular imprinting solid phase microextraction(MISPME-) HPLC [11].

SPE is the most popular preconcentration method, because of high extraction efficiency, low consumption of organic solvent, low extraction time, and easy operation. Recently nanometer size particles $\left(\mathrm{NP}_{\mathrm{S}}\right)$ have gained rapid and substantial progress and have significantly impacted on sample extraction [12-14]. Among different kinds of $\mathrm{MNP}_{\mathrm{s}}$, mainly including $\mathrm{Fe}_{3} \mathrm{O}_{4}$, nanoparticles were used as solid phase extraction (SPE) sorbents for preconcentration of several organic and inorganic compounds [15-18]; because of their unique size and superparamagnetic property, these particles have an interesting advanced composite material.

Magnetic nanoparticles offer many advantages over the traditional sorbents. They have very large surface area, highly active surface sites, and a short diffusion route. These particles tagged to the target can be removed from a matrix quickly by applying a magnetic field and do not agglomerate after removal of the field and can be reused or recycled easily; however, these nanometer sized metal oxides are not target-selective; therefore, overcoming this limitation modification of these magnetic nanoparticles is necessary [19-22]. Hemimicelles and admicelles are formed by the adsorption of ionic surfactants on surface of mineral oxides such as alumina, silica, titanium dioxide, and iron oxides [23] and have recently been employed as useful sorbent for the SPE of some organic compounds [24]. Few SPE methods based on surfactant-coated $\mathrm{Fe}_{3} \mathrm{O}_{4} \mathrm{NP}_{\mathrm{S}}$ have been reported [25]. We report here a fast and selective method based on magnetic nanoparticles modified by CTAB for the extraction and determination of residual four nonsteroidal anti-inflammatory drugs in aqueous solution that so far has not been reported for these drugs with this method.

\section{Experimental}

2.1. Instruments, Reagents, and Materials. All reagents used were of analytical-reagent grade and all aqueous solutions were prepared using doubly distilled deionized water. The water was purified on a Mili-Q-ultrapure water purification system purchased from Milipore (Milford, MA,USA). Ferric chloride $\left(\mathrm{FeCl}_{3} \cdot 6 \mathrm{H}_{2} \mathrm{O}\right)$, ferrous chloride $\left(\mathrm{FeCl}_{2} \cdot 4 \mathrm{H}_{2} \mathrm{O}\right)$, cetyltrimethylammonium bromide (CTAB), methanol, acetonitrile, ethanol, hydrochloric acid, potassium dihydrogen phosphate, and sodium hydroxide were obtained from Merck, Germany. Naproxen (NAP), indomethacin (INDO), diclofenac (DICLO), and ibuprofen (IBU) were obtained from Daroupakhsh Drug Company (Tehran, Iran). Wastewater samples were obtained from Daroupakhsh Drug Company, and the fresh urine samples were obtained from different women patients who had or had not taken these drugs and stored at $4^{\circ} \mathrm{C}$ until analysis.

For magnetic separations a strong magnet of $\mathrm{NdFeB}(10 \times$ $5 \times 4 \mathrm{~cm}$ ) was used. A HPLC (Waters, USA) system equipped with a 515 (Waters, USA) pump and a Photo Diode Array996 detector was used. The sample injection volume was set to $20 \mu \mathrm{L}$. A pH meter model-713 from Metrohm, Swiss, was used. The Vortex from IKA (USA), ultrasonic, was from Bandeline Sonorex (USA), transmission electron microscopy (TEM) was from Philips EM208 (Voltage $100 \mathrm{KV}$ ), and a centrifuge model Celements GS-200 (USA) was used.

2.2. HPLC Analysis and Characterization. The stationaryphase column was $C_{18}$, Luna $(5 \mu \mathrm{m}-250 \times 4.6 \mathrm{~mm})$ from Phenomenex (USA). A mixture of $0.02 \mathrm{M}$ phosphate buffer $(\mathrm{pH}=6.02)$ and acetonitrile $(65: 35 v / v)$ was used as mobile phase and its flow rate was set at $1 \mathrm{~mL} \mathrm{~min}^{-1}$. The oven temperature was set at $25^{\circ} \mathrm{C}$ and the detection was made at the wavelength of $202 \mathrm{~nm}$. The retention time for methanol as a solvent was $3 \mathrm{~min}$, and retention times for NAP, INDO, DICLO, and IBU were 7.4, 15.9, 17.4, and $19.4 \mathrm{~min}$, respectively.

2.3. Preparation of Standard Solutions and Real Samples. Stock solutions of NAP, INDO, DICLO, and IBU were prepared in methanol + phosphate buffer $(\mathrm{pH}=7.2)(50: 50$ $v / v)$ and stored in dark glass/bottles at $4^{\circ} \mathrm{C}$. Under these conditions, they were stable at least for one month. Working solutions $\left(10 \mathrm{mg} \cdot \mathrm{L}^{-1}\right.$ naproxen, indomethacin, sodium diclofenac, and ibuprofen) were prepared daily by appropriate dilution of the corresponding stock solution in the same solvent. Urine samples were stored at $4^{\circ} \mathrm{C}$ until analysis. The $\mathrm{pH}$ of the urine samples was adjusted to 12.0 by drop wise addition of $\mathrm{NaOH}(6 \mathrm{M})$ solution. The urine samples were centrifuged at $3000 \mathrm{rpm}$ for $20 \mathrm{~min}$ at room temperature and the supernatant was diluted $(1: 10)$ with deionized water. The dilution of the urine could suppress the matrix and prevent the contamination of the sorbents. Wastewater samples were collected and filtered with Millipore filter before extraction. The calibration curve for each drug was achieved by simple linear regression of each drug's peak area versus its concentration, and the concentrations of analytes in real samples were calculated on the basis of calibration curves.

2.4. Synthesis and Characterization of $\mathrm{Fe}_{3} \mathrm{O}_{4} N P_{s}$. $\mathrm{Fe}_{3} \mathrm{O}_{4}$ nanoparticles were prepared by the chemical coprecipitation method as follows: $10.4 \mathrm{~g}$ of $\mathrm{FeCl}_{3} \cdot 6 \mathrm{H}_{2} \mathrm{O}, 4 \mathrm{~g}$ of $\mathrm{FeCl}_{2} \cdot 4 \mathrm{H}_{2} \mathrm{O}$, and $1.7 \mathrm{~mL}$ of $\mathrm{HCl}\left(12 \mathrm{~mol} \cdot \mathrm{L}^{-1}\right)$ were dissolved in $50 \mathrm{~mL}$ of deionized and degassed water with ultrasonic to prepare a stock solution. $500 \mathrm{~mL}$ of $1.5 \mathrm{~mol} \cdot \mathrm{L}^{-1} \mathrm{NaOH}$ solution was heated to $80^{\circ} \mathrm{C}$ in a beaker (degassed with ultrasonic), the stock solution was added dropwise during $30 \mathrm{~min}$ under nitrogen gas protection, and vigorous stirring was done by a stirrer $(1000 \mathrm{rpm})$ to prevent the oxidation of $\mathrm{Fe}^{2+}$ ions [26]. During the whole process, the temperature of the solution was maintained at $80^{\circ} \mathrm{C}$ and nitrogen gas was used to prevent the intrusion of oxygen. After completion of the reaction, the obtained $\mathrm{Fe}_{3} \mathrm{O}_{4} \mathrm{NP}_{\mathrm{s}}$ precipitate was separated from the reaction medium by magnetic field and washed with $500 \mathrm{~mL}$ 
deionized water four times. Finally, the obtained $\mathrm{MNP}_{\mathrm{s}}$ were resuspended in $500 \mathrm{~mL}$ of the degassed deionized water. The $\mathrm{pH}$ of obtained suspension was 11.0 and the concentration of the generated $\mathrm{MNP}_{\mathrm{s}}$ in suspension was estimated to be about $10 \mathrm{mg} \cdot \mathrm{mL}^{-1}$. The obtained $\mathrm{MNP}_{\mathrm{s}}$ were stable up to one month. The synthesized $\mathrm{MNP}_{\mathrm{s}}$ were characterized using TEM as shown in Figure 1. As it can be seen the particles diameters are lower than $50 \mathrm{~nm}$.

2.5. Extraction Procedure. Optimization studies were carried out according to the following procedure: by the addition of appropriate volume of the drug's stock solution in $20 \mathrm{~mL}$ of distilled water, the aqueous solution of each drug $(100 \mathrm{ng} / \mathrm{mL})$ was prepared and then $0.75 \mathrm{~mL}$ of the MNP suspension (containing $10 \mathrm{mg}$ of $\mathrm{Fe}_{3} \mathrm{O}_{4} \mathrm{NP}_{\mathrm{s}}$ ) was added to the drug's solution and the $\mathrm{pH}$ was adjusted to 8.5 . Then, $0.5 \mathrm{~mL}$ of the $10 \mathrm{mg} \cdot \mathrm{mL}^{-1}$ CTAB was added and the mixture was shaken for $5 \mathrm{~min}$ to enhance the drug's adsorption efficiency and then by use of a strong magnet $\mathrm{Fe}_{3} \mathrm{O}_{4} \mathrm{NP}_{\mathrm{s}}$ placed at the bottom of the beaker was separated quickly from sample solution. The magnet was removed and the supernatant water was decanted. Finally the drugs were desorbed with $500 \mu \mathrm{L}$ methanol from $\mathrm{MNP}_{\mathrm{s}}$. Calculation of ER\% showed that desorption of drugs was completed during $30 \mathrm{~s}$ in ultrasonic bath and $30 \mathrm{~s}$ in vortex. The magnet was used again to settle the $\mathrm{MNP}_{\mathrm{s}}$ and the eluent was decanted into a microtube; then, $20 \mu \mathrm{L}$ of the solution was injected into the HPLC instrument for analysis. All the experiments were carried out at the room temperature. The preconcentration factor $(\mathrm{PF})$ and extraction recovery (ER) of the drugs were calculated by the following equations:

$$
\begin{gathered}
\mathrm{PF}=\frac{C_{E, \text { final }}}{C_{s, \text { initial }}} \times 100, \\
\mathrm{ER} \%=\frac{n_{E}}{n_{S}} \times 100=\left(\frac{C_{E \text {,final }} \times V_{E, \text { final }}}{C_{s, \text { initial }} \times V_{s, \text { initial }}}\right) \times 100, \\
\mathrm{ER} \%=\left(\frac{V_{E, \text { final }}}{V_{s, \text { initial }}}\right) \times \mathrm{PF} \times 100,
\end{gathered}
$$

where $C_{E \text {,final }}$ and $C_{S \text {,initial }}$ are the final and initial concentrations of the drug in the eluent and the sample, respectively. $C_{E \text {,final }}$ of the extracted drug was calculated from the calibration curve. $V_{S}$ and $V_{E}$ are the volumes of the sample solution and eluent, respectively.

\section{Result and Discussion}

3.1. Effect of $p H$. In order to obtain the highest recovery the effect of different parameters on the performance of the method was investigated. The charge density of mineral oxide surface is a main factor affecting the adsorption of analytes and it varies with $\mathrm{pH}$. Thus, $\mathrm{pH}$ is a very important parameter for the adsorption of target compounds. The isoelectric point at $\mathrm{pH}=6.5\left(\mathrm{pH}_{\mathrm{zpc}}\right)$ for the $\mathrm{Fe}_{3} \mathrm{O}_{4}$ nanoparticles was reported previously [27]. At the $\mathrm{pH}$ higher than $\mathrm{pH}_{\mathrm{zpc}}$, the negative charge density on the surface of the $\mathrm{Fe}_{3} \mathrm{O}_{4} \mathrm{NP}_{\mathrm{s}}$ is increased. As a result, the adsorption of CTAB as a cationic surfactant on

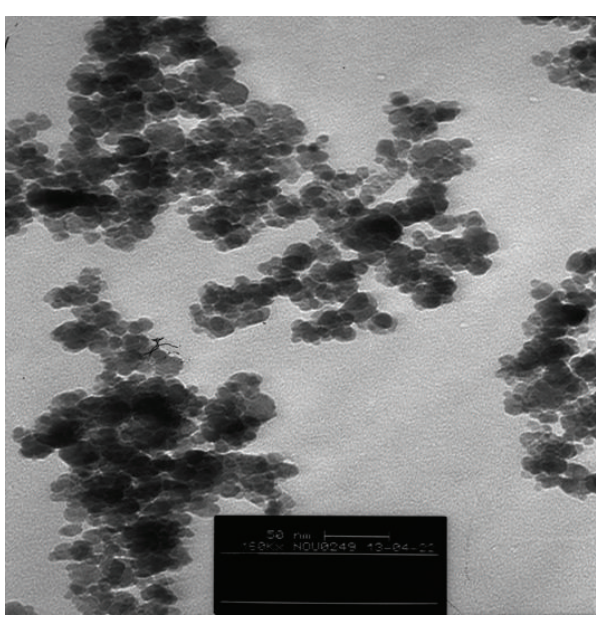

FIGURE 1: The TEM image of the synthesized $\mathrm{MNP}_{\mathrm{s}}$, magnification 160000 .

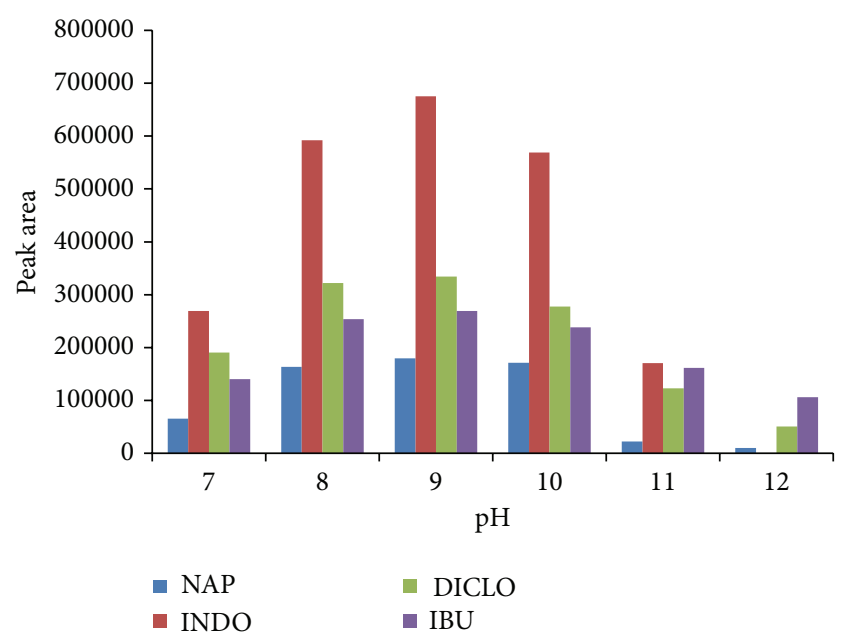

Figure 2: Adsorption efficiency of CTAB-coated $\mathrm{MNP}_{\mathrm{s}}$ as a function of samples $\mathrm{pH}$.

the surface is also increased; therefore, extraction efficiency is increased. The effect of $\mathrm{pH}$ on adsorption performance of drugs was studied over a $\mathrm{pH}$ range of $7-12$ for CTAB-coated $\mathrm{MNP}_{\mathrm{s}}$. The adsorption performance of drugs are illustrated in Figure 2. The results indicate that maximum adsorption takes place at $\mathrm{pH}=8.5$.

3.2. Influence of $C T A B$ Concentration. The outer surface of hemimicelles is hydrophobic whereas that of admicelles is ionic and provides different mechanisms for retention of organic compounds which are suitable in the SPE method. In mixed hemimicelles phase, both hemimicells and micelles are formed on the surface of mineral oxides and the desorption is driven by both hydrophobic interactions and electrostatic attraction. Surfactant can form different structure on surface of metal oxides. The influence of surfactant content was studied by adding different amounts of cationic surfactant. Figure 3 depicts the adsorption performance of drugs as 


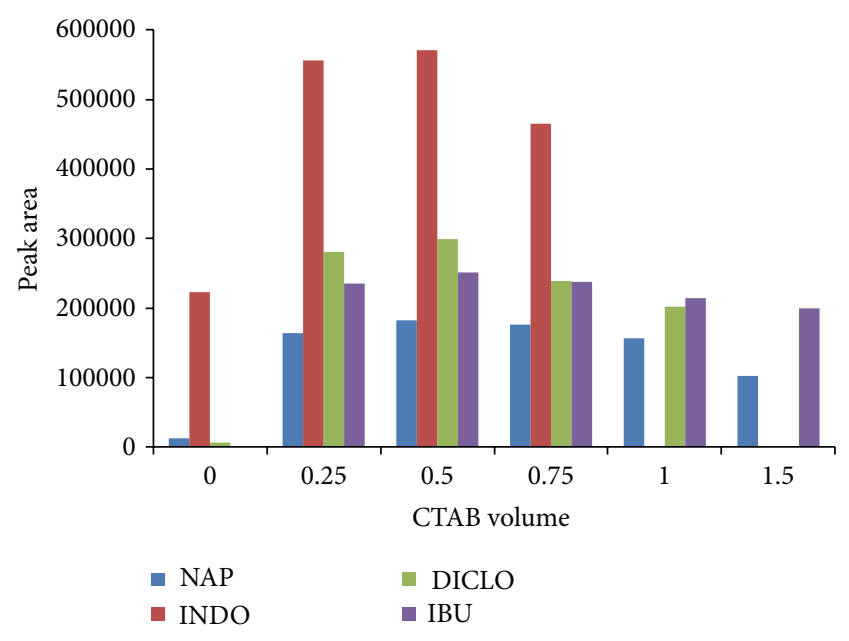

FIGURE 3: The adsorption performance of nonsteroidal antiinflammatory drugs as a function of the amount of CTAB added.

a function of the amount of added CTAB. At low concentration of $\mathrm{CTAB}$, the adsorption performance of the drugs on to the surface of $\mathrm{MNP}_{\mathrm{s}}$ is low. In contrast, by increasing CTAB concentration, the formation of micelles in the bulk solution takes place. Therefore, when surfactant concentration was above the critical micelle concentration (CMC), the adsorption of analytes decreased gradually. Increase in the adsorption performance can be explained by the gradual formation of hydrophobic hemimicelles on the surface of $\mathrm{MNP}_{s}$, which can increase adsorption performance of the drugs; these results are concurrent with reported literature data $[28,29]$. Hemimicelles consisting of a monolayer of surfactant is adsorbed head down on a positively charged surface when $0.5 \mathrm{~mL}$ of CTAB with concentration $10 \mathrm{mg} \cdot \mathrm{mL}^{-1}$ was used.

3.3. Salt Effect. It is reported that the addition of salt to the samples has been beneficial for the extraction efficiency of many compounds in SPME [30]. Therefore, effect of salt addition in the range $0-10 \%(w / v)$ was studied on adsorption efficiency of the drugs. The results indicated that the maximum adsorption was obtained when $\mathrm{NaCl}$ was not used. That can be explained by the thickness of CTAB adsorption layer on the surface of $\mathrm{MNP}_{s}$ which led to decrease in mixed hemimicelles layer formed. Hence, no salt was added in the subsequent experiments.

3.4. Stirring and Magnetic Separation. In order to obtain maximum extraction efficiency, effect of the extraction time was investigated in the range of 1-10 min. Results reveal that a rapid extraction occurs in about $5 \mathrm{~min}$. Then, a time of $5 \mathrm{~min}$ was chosen for further studies. The high surface area of $\mathrm{MNP}_{\mathrm{s}}$ along with homogenous distribution of the nanosorbent throughout the sample could be the possible reason for achieving such fast extraction. Therefore, analysis time is shortened greatly compared with the traditional flowor-batch type SPE.
3.5. Effect of Sample Volume. In order to obtain a higher enrichment factor, a larger volume of sample solution is required. Thus, the extraction of $100 \mathrm{ppb}$ of drugs from different volumes of the water samples ranging from 20 to $80 \mathrm{~mL}$ was investigated. It was showed that the best quantitative recovery was obtained when the sample volume was $20 \mathrm{~mL}$. The larger volume of sample leads to the analyte loss from the sorbent surface. Hence, $20 \mathrm{~mL}$ of sample volume was selected as the ideal volume for trace analysis of drugs in water samples.

3.6. Effect of the Amount of Nanoparticle Sorbent. Compared to traditional sorbents, nanoparticle sorbents have higher surface areas. Thus, satisfactory results can be obtained with lower amounts of nanoparticle sorbents. In order to study the effect of the adsorbent, different amounts of nanosorbents $\left(0.5-2 \mathrm{~mL}\right.$ of $10 \mathrm{mg} / \mathrm{mL}$ of $\left.\mathrm{Fe}_{3} \mathrm{O}_{4} \mathrm{NP}_{\mathrm{s}}\right)$ were added to $20 \mathrm{~mL}$ of the sample solution. The obtained results showed that by increasing the amount of $\mathrm{Fe}_{3} \mathrm{O}_{4} \mathrm{NP}_{\mathrm{s}}$ that are modified with $\mathrm{CTAB}$, extraction efficiency was increased slowly due to the increasing of accessible sites; therefore, $0.75 \mathrm{~mL}$ of the $\mathrm{Fe}_{3} \mathrm{O}_{4} \mathrm{NP}_{\mathrm{s}}$ was selected for all subsequent experiments.

3.7. Desorption Condition and Desorption Time. Organic solvents are known to disrupt mixed hemimicelles structures. Therefore, to find the best eluent, different organic solvents (methanol; acetonitrile; ethanol) were tested. The maximum signal was observed when methanol was used in comparison with other solvents for desorption of these drugs from the surface of the CTAB-Coated- $\mathrm{Fe}_{3} \mathrm{O}_{4} \mathrm{NP}_{s}$. The effect of the volume of the eluent was also tested $(200-1000 \mu \mathrm{L})$. The best results were obtained with $500 \mu \mathrm{L}$ of methanol. Effect of time of ultrasonic and shaking were also investigated in the range of 10-60 s that $20 \mathrm{~s}$ was found as best desorption time.

3.8. Optimization of Measurement Conditions. The analytical features of the proposed method such as linear range of calibration curve (correlation coefficient), preconcentration factor, limit of detection (LOD), and extraction recovery were also examined. The results are summarized in Table 1. It can be seen that the present method has high sensitivity, wide linear ranging with three replicate measurements for each point, and good method precision. The limits of detection were calculated by using signal to noise ratio of 3. It was found that preconcentration factors are in the range of (36.70-38.49) $\left(V_{\text {sample }}=20 \mathrm{~mL}\right)$ and the extraction recovery percentage values are in the range of (91.76-96.24)\%. The $\mathrm{LOD}_{s}$ were obtained at the range of $(2-7) \mathrm{ng} \cdot \mathrm{mL}^{-1}$. The relative standard deviation (R.S.D) for the determination of 25,50 , and $200 \mathrm{ng} \cdot \mathrm{mL}^{-1}$ of drugs were fine and are recorded in Table $2(n=6)$. A comparison of the features of present developed method with other reported methods for extraction and determination of nonsteroidal anti-inflammatory drugs is recorded in Table 4 which clearly shows the analytical superiority of this present method.

3.9. Analysis of the NSAID from Human Urine and Wastewater Samples. Owing to the importance of analysis of drugs 
TABLE 1: Analytical characteristics of SPE based on CATB-coated $\mathrm{MNP}_{\mathrm{s}}$ for the determination of nonsteroidal anti-inflammatory drugs.

\begin{tabular}{lcccccc}
\hline Analyte & LOD $\left(\mathrm{ngmL}^{-1}\right)^{\mathrm{a}}$ & $R^{2}$ & Regression equation & LDR $\left._{(\mathrm{ngmL}}^{-1}\right)^{\mathrm{b}}$ & PF & ER\% \\
\hline DICLO & 7 & 0.997 & $A=1.042 \mathrm{C}\left(\mu \mathrm{gL}^{-1}\right)+2.537$ & $10-200$ & 36.70 & 91.76 \\
INDO & 2 & 0.996 & $A=3.939 C\left(\mu \mathrm{gL}^{-1}\right)-9.662$ & $2.5-400$ & 38.49 & 96.24 \\
IBU & 3 & 0.999 & $A=2.128 C\left(\mu \mathrm{gL}^{-1}\right)-6.848$ & $5-400$ & 37.74 \\
NAP & 2 & 0.999 & $A=1.514 \mathrm{C}\left(\mu \mathrm{gL}^{-1}\right)-1.325$ & $10-400$ & 94.36 \\
\hline
\end{tabular}

${ }^{\text {a }}$ Limit of detection.

${ }^{\mathrm{b}}$ Linear dynamic range.

TABLE 2: Average relative standard deviation (RSD) for spiked drugs $(n=6)$.

\begin{tabular}{lccc}
\hline Analyte & $25 \mathrm{ng} \cdot \mathrm{mL}^{-1}$ & $50 \mathrm{ng} \cdot \mathrm{mL}^{-1}$ & $200 \mathrm{ng} \cdot \mathrm{mL}^{-1}$ \\
\hline DICLO & $10.94 \%$ & $9.83 \%$ & $8.16 \%$ \\
INDO & $7.02 \%$ & $6.61 \%$ & $4.45 \%$ \\
IBU & $5.86 \%$ & $3.98 \%$ & $3.85 \%$ \\
NAP & $5.53 \%$ & $4.11 \%$ & $3.73 \%$ \\
\hline
\end{tabular}

in biological samples and wastewater in pharmaceutical company the proposed method was applied to determine the concentration of the $\mathrm{NSAID}_{\mathrm{S}}$ in urine and wastewater samples. Initially the wastewater samples were spiked with four drugs at different concentrations and the extraction was performed under optimized condition. In urine sample, in order to reduce the matrix effect, $\mathrm{pH}$ was adjusted at 12.0 by adding $\mathrm{NaOH}$; then, they were diluted tenfold with deionized water. In the next step each real sample was extracted under optimal conditions by the proposed procedure. The obtained results are recorded in Table 3 . The results showed that no analyte in the nonspiked real samples was found.

The chromatograms of the patient urine sample are shown in Figures 4(a) and 4(b). The chromatograms of the outlet wastewater samples with $25 \mathrm{ng} / \mathrm{mL}$ concentration level of the target drugs are shown in Figures 5(a) and 5(b). These chromatograms reveal a good cleanup of the proposed method to determine drug concentration in the urine samples. Also, the obtained results for the spike urine samples are in reasonable agreement with the respective values.

\section{Conclusion}

A new rapid and sensitive method for preconcentration and determination of residual of four $\left(\mathrm{NSAID}_{\mathrm{s}}\right)$ drugs in wastewater and urine samples has been developed based on use of superparamagnetic CTAB-coated magnetic nanoparticles. It is clear that in comparison to other reported methods the present developed method has striking advantages such as high sensitivity, consuming low amount of organic solvent $(500 \mu \mathrm{L})$, short analysis time $(17 \mathrm{~min})$, and employing small amount of nanoparticles sorbent due to their higher surface area. Further no centrifugation or filtration required for removal of magnetic CTAB-coated nanoparticles. These advantages together with the inherent high sensitivity and selectivity of HPLC make this method a reliable and robust
TABLE 3: Determination of the INDO in wastewater and INDO, IBU in urine samples.

\begin{tabular}{|c|c|c|}
\hline Sample & INDo & $\mathrm{IBu}$ \\
\hline \multicolumn{3}{|l|}{ (1) Inlet of wastewater } \\
\hline Initial concentration $\left(\mu \mathrm{g} \cdot \mathrm{L}^{-1}\right)$ & 1.91 & - \\
\hline $\mathrm{RSD} \%$ & 6.41 & - \\
\hline \multicolumn{3}{|l|}{$\begin{array}{l}\text { (2) Inlet of wastewater } \\
\left(25 \mu \mathrm{g} \cdot \mathrm{L}^{-1} \text { of the drug was added) }\right.\end{array}$} \\
\hline Found & 25.83 & - \\
\hline $\mathrm{RSD} \%$ & 5.24 & - \\
\hline Preconcentration factor & 38.39 & - \\
\hline \multicolumn{3}{|l|}{ (3) Outlet of wastewater } \\
\hline Initial concentration $\left(\mu \mathrm{g} \cdot \mathrm{L}^{-1}\right)$ & - & \\
\hline \multicolumn{3}{|l|}{$\begin{array}{l}\text { (4) Outlet of wastewater } \\
\left(25 \mu \mathrm{g} \cdot \mathrm{L}^{-1} \text { of the drug was added) }\right.\end{array}$} \\
\hline Found & 24.71 & - \\
\hline $\mathrm{RSD} \%$ & 4.93 & - \\
\hline Preconcentration factor & 39.53 & - \\
\hline \multicolumn{3}{|l|}{$\begin{array}{l}\text { (5) Urine (patient) } \\
\text { (100 } \mu \mathrm{g} \cdot \mathrm{L}^{-1} \text { of the drugs was added) }\end{array}$} \\
\hline Initial concentration $\left(\mu \mathrm{g} \cdot \mathrm{L}^{-1}\right)$ & 10.10 & 689.89 \\
\hline Found & 107.61 & 751.37 \\
\hline RSD \% & 4.11 & 1.70 \\
\hline Preconcentration factor & 39.09 & 38.05 \\
\hline \multicolumn{3}{|l|}{$\begin{array}{l}\text { (6) Urine } \\
\text { (100 } \mu \mathrm{g} / \text { Lit of the drug was added) }\end{array}$} \\
\hline Initial concentration & - & - \\
\hline Found & 100.07 & 97.45 \\
\hline $\mathrm{RSD} \%$ & 4.66 & 3.93 \\
\hline Preconcentration factor & 40.02 & 38.98 \\
\hline
\end{tabular}

methodology for trace analysis of organic and biological species in a variety of samples. 
TABLE 4: Comparison of the proposed method with other analytical methods for the determination of different nonsteroidal antiinflammatory drugs in various samples.

\begin{tabular}{|c|c|c|c|c|c|c|c|}
\hline $\begin{array}{l}\text { Analytical } \\
\text { technique }\end{array}$ & Matrix & Linear range & $R^{2}$ & LOD & $\mathrm{ER} \%$ & RSD\% & Reference \\
\hline $\begin{array}{l}\text { HFLPME-HPLC } \\
\text { (Ibu-Diclo) }\end{array}$ & Urine & $(135-10000) \mathrm{ng} / \mathrm{mL}$ & $>0.99$ & $(41-53)$ ngmL $^{-1}$ & $99 \%$ & & [9] \\
\hline SPME-HPLC (Ibu) & Urine & $(5-50) \mu \mathrm{gmL}^{-1}$ & $>0.98$ & $5 \mu \mathrm{gmL}^{-1}$ & (3.7-5.7) \% & $<13.4$ & {$[6]$} \\
\hline $\begin{array}{l}\text { Supra molecular } \\
\text { SPE-LC (Nap-Ibu) }\end{array}$ & Sewage & $\begin{array}{l}\text { Ibu }(0.2-750) \mathrm{ng} \\
\text { Nap }(0.02-250) \mathrm{ng}\end{array}$ & $\begin{array}{l}>0.99 \\
>0.99\end{array}$ & $\begin{array}{c}0.8 \mathrm{ngmL}^{-1} \\
9 \mathrm{ngmL}^{-1}\end{array}$ & $(93-101) \%$ & $(2-9) \%$ & {$[8]$} \\
\hline $\begin{array}{l}\text { SPE-LC } \\
\text { (Diclo-Indo) }\end{array}$ & Urine & $(0.02-1.0) \mu \mathrm{gmL}^{-1}$ & $>0.99$ & $\begin{array}{c}0.007- \\
0.035 \mu \mathrm{gL}^{-1}\end{array}$ & $(85-85) \%$ & $\begin{array}{l}\text { Diclo }(0.95-9.8) \% \\
\text { Indo }(0.62-8.7) \%\end{array}$ & {$[7]$} \\
\hline $\begin{array}{l}\text { MSPE-HPLC } \\
\text { (NSAIDs) }\end{array}$ & Urine and sewage & $(7-200) \mathrm{ng} / \mathrm{mL}$ & $>0.99$ & $(2-7) \mathrm{ng} / \mathrm{mL}$ & $(91.76-96.24) \%$ & $(3.98-9.83) \%$ & This work \\
\hline
\end{tabular}

SPME: solid phase micro extraction; SPE: solid phase extraction; HFLPME: hollow fiber liquid phase microextraction; $\mathrm{MNP}_{\mathrm{s}}$ : magnetic nanoparticles.

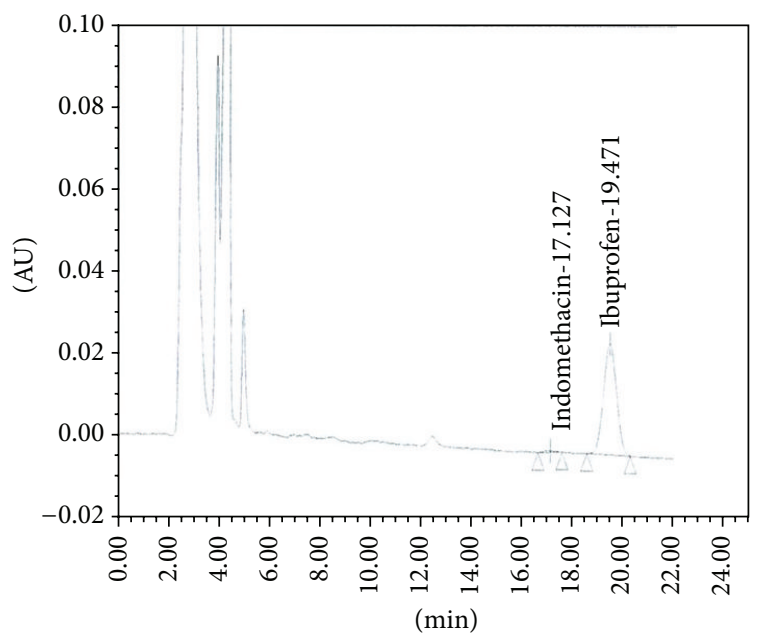

(a)

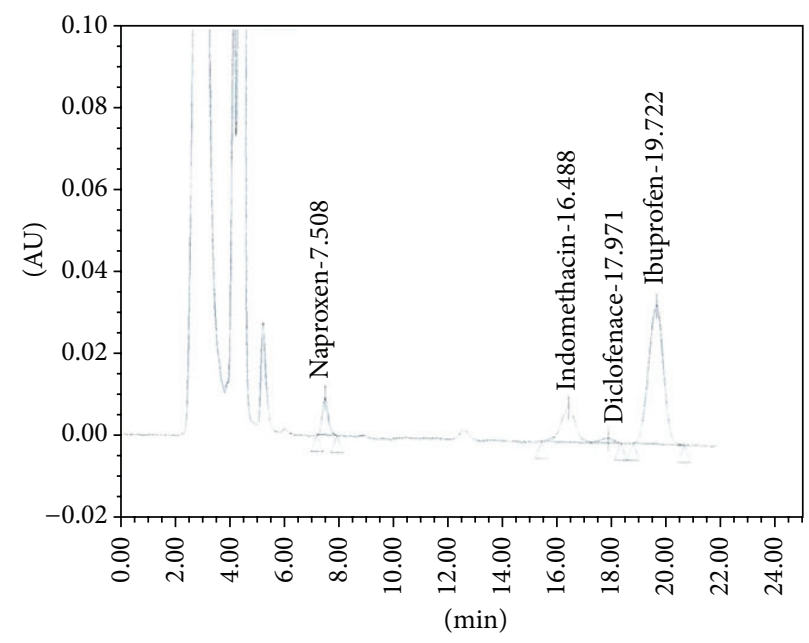

(b)

Figure 4: Chromatograms for nonsteroidal anti-inflammatory drugs (a) in a patient urine sample and (b) in a spike patient urine sample at $100 \mu \mathrm{gL}^{-1}$.

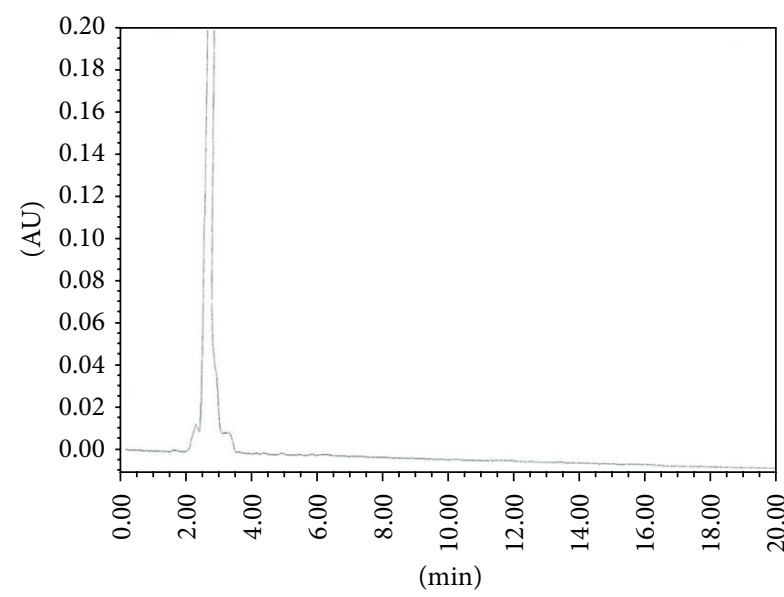

(a)

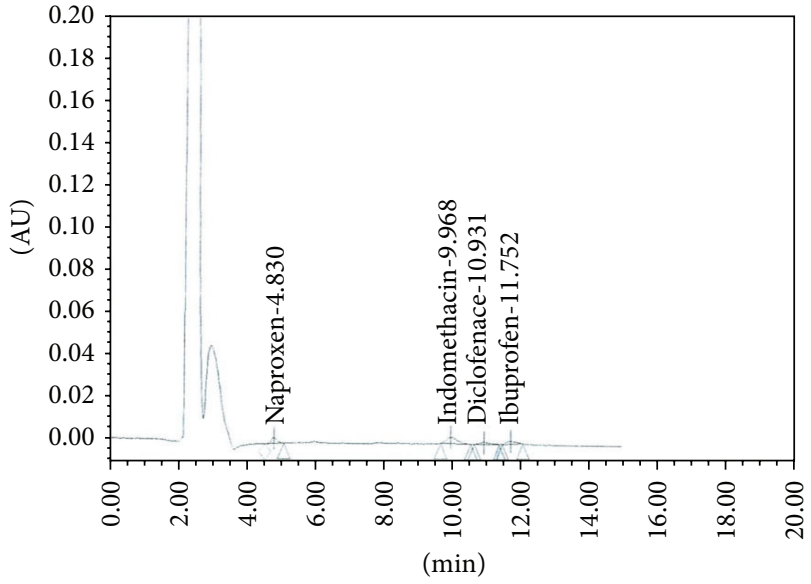

(b)

FIGURE 5: Chromatograms for nonsteroidal anti-inflammatory drugs (a) in an outlet wastewater and (b) in a spike outlet wastewater sample at $25 \mu \mathrm{g} \mathrm{L}$. 


\section{Conflict of Interests}

The authors declare that they have no conflict of interests regarding the publication of this paper.

\section{Acknowledgments}

This study was supported by the Islamic Azad University of Science and Research Branch. Authors are thankful to Hossein Afrouzi (Department of Chemistry, Faculty of Science, Lorestan University, Khorramabad, Iran) who provided support during this study.

\section{References}

[1] C.-S. Su and Y.-P. Chen, "Measurement and correlation for the solid solubility of non-steroidal anti-inflammatory drugs (NSAIDs) in supercritical carbon dioxide," Journal of Supercritical Fluids, vol. 43, no. 3, pp. 438-446, 2008.

[2] E. H. Ruder, A. O. Laiyemo, B. I. Graubard, A. R. Hollenbeck, A. Schatzkin, and A. J. Cross, "Non-steroidal anti-inflammatory drugs and colorectal cancer risk in a large, prospective cohort," The American Journal of Gastroenterology, vol. 106, no. 7, pp. 1340-1350, 2011.

[3] A. Nikolaou, S. Meric, and D. Fatta, "Occurrence patterns of pharmaceuticals in water and wastewater environments," Analytical and Bioanalytical Chemistry, vol. 387, no. 4, pp. 12251234, 2007.

[4] K. Kümmerer, "The presence of pharmaceuticals in the environment due to human use-present knowledge and future challenges," Journal of Environmental Management, vol. 90, no. 8, pp. 2354-2366, 2009.

[5] S. K. Khetan and T. J. Collins, "Human pharmaceuticals in the aquatic environment: a challenge to green chemisty," Chemical Reviews, vol. 107, no. 6, pp. 2319-2364, 2007.

[6] A. R. M. de Oliveira, F. J. M. de Santana, and P. S. Bonato, "Stereoselective determination of the major ibuprofen metabolites in human urine by off-line coupling solid-phase microextraction and high-performance liquid chromatography," Analytica Chimica Acta, vol. 538, no. 1-2, pp. 25-34, 2005.

[7] T. Hirai, S. Matsumoto, and I. Kishi, "Simultaneous analysis of several non steroidal anti inflammatory drugs in human urine by high performance liquid chromatography with normal solid phase extraction," Journal of Chromatography B, vol. 692, pp. 375-388, 1997.

[8] E. M. Costi, I. Goryacheva, M. D. Sicilia, S. Rubio, and D. PérezBendito, "Supramolecular solid-phase extraction of ibuprofen and naproxen from sewage based on the formation of mixed supramolecular aggregates prior to their liquid chromatographic/photometric determination," Journal of Chromatography A, vol. 1210, no. 1, pp. 1-7, 2008.

[9] M. R. Payán, M. Á. B. López, R. Fernández-Torres, J. L. P. Bernal, and M. C. Mochón, "HPLC determination of ibuprofen, diclofenac and salicylic acid using hollow fiber-based liquid phase microextraction (HF-LPME)," Analytica Chimica Acta, vol. 653, no. 2, pp. 184-190, 2009.

[10] K. Farrington and F. Regan, "Investigation of the nature of MIP recognition: the development and characterisation of a MIP for Ibuprofen," Biosensors and Bioelectronics, vol. 22, no. 6, pp. 11381146, 2007.
[11] H. Parham, N. Pourreza, and N. Rahbar, "Solid phase extraction of lead and cadmium using solid sulfur as a new metal extractor prior to determination by flame atomic absorption spectrometry," Journal of Hazardous Materials, vol. 163, no. 23, pp. 588-592, 2009.

[12] W. Ngeontae, W. Aeungmaitrepirom, and T. Tuntulani, "Chemically modified silica gel with aminothioamidoanthraquinone for solid phase extraction and preconcentration of $\mathrm{Pb}(\mathrm{II})$, $\mathrm{Cu}(\mathrm{II}), \mathrm{Ni}(\mathrm{II}), \mathrm{Co}(\mathrm{II})$ and $\mathrm{Cd}(\mathrm{II}), "$ Talanta, vol. 71, no. 3, pp. 1075-1082, 2007.

[13] Y. Song, S. Zhao, P. Tchounwou, and Y.-M. Liu, "A nanoparticle-based solid-phase extraction method for liquid chromatography-electrospray ionization-tandem mass spectrometric analysis," Journal of Chromatography A, vol. 1166, no. 1-2, pp. 79-84, 2007.

[14] S. Čampelj, D. Makovec, and M. Drofenik, "Functionalization of magnetic nanoparticles with 3-aminopropyl silane," Journal of Magnetism and Magnetic Materials, vol. 321, no. 10, pp. 13461350, 2009.

[15] A. K. Gupta and M. Gupta, "Synthesis and surface engineering of iron oxide nanoparticles for biomedical applications," Biomaterials, vol. 26, no. 18, pp. 3995-4021, 2005.

[16] W. Yantasee, C. L. Warner, T. Sangvanich et al., "Removal of heavy metals from aqueous systems with thiol functionalized superparamagnetic nanoparticles," Environmental Science and Technology, vol. 41, no. 14, pp. 5114-5119, 2007.

[17] H. Parham and N. Rahbar, "Solid phase extraction-spectrophotometric determination of salicylic acid using magnetic iron oxide nanoparticles as extractor," Journal of Pharmaceutical and Biomedical Analysis, vol. 50, no. 1, pp. 58-63, 2009.

[18] X. Zhao, Y. Shi, T. Wang, Y. Cai, and G. Jiang, "Preparation of silica-magnetite nanoparticle mixed hemimicelle sorbents for extraction of several typical phenolic compounds from environmental water samples," Journal of Chromatography A, vol. 1188, no. 2, pp. 140-147, 2008.

[19] M. Faraji, Y. Yamini, and M. Rezaee, "Magnetic nanoparticles: synthesis, stabilization, functionalization, characterization, and applications," Journal of the Iranian Chemical Society, vol. 7, no. 1, pp. 1-37, 2010.

[20] A. Mehdinia, T. B. Kayyal, A. Jabbari, M. O. A. Zanjani, and E. Ziaei, "Magnetic molecularly imprinted nanoparticles based on grafting polymerization for selective detection of 4-nitrophenol in aqueous sample," Journal of Chromatography A, vol. 1283, pp. 82-88, 2013.

[21] A. Afkhami, M. Saber-Tehrani, and H. Bagheri, "Simultaneous removal of heavy-metal ions in wastewater samples using nanoalumina modified with 2,4-dinitrophenylhydrazine," Journal of Hazardous Materials, vol. 181, no. 1-3, pp. 836-844, 2010.

[22] S. S. E. Aboobakri and S. Sadeghi, "Magnetic nanoparticles with an imprinted polymer coating for the selective extraction of uanyl ions," Journal of Micro Chimica Acta, vol. 178, pp. 89-97, 2012.

[23] X. Zhao, J. Li, Y. Shi, Y. Cai, S. Mou, and G. Jiang, "Determination of perfluorinated compounds in wastewater and river water samples by mixed hemimicelle-based solid-phase extraction before liquid chromatography-electrospray tandem mass spectrometry detection," Journal of Chromatography A, vol. 1154, no. 1-2, pp. 52-59, 2007.

[24] F. Merino, S. Rubio, and D. Pérez-Bendito, "Evaluation and optimization of an on-line admicelle-based extraction-liquid chromatography approach for the analysis of ionic organic 
compounds," Analytical Chemistry, vol. 76, no. 14, pp. 38783886, 2004.

[25] M. Faraji, Y. Yamini, and M. Rezaee, "Extraction of trace amounts of mercury with sodium dodecyle sulphate-coated magnetite nanoparticles and its determination by flow injection inductively coupled plasma-optical emission spectrometry," Talanta, vol. 81, no. 3, pp. 831-836, 2010.

[26] M. Faraji, Y. Yamini, E. Tahmasebi, A. Saleh, and F. Nourmohammadian, "Cetyltrimethylammonium bromide-coated magnetite nanoparticles as highly efficient adsorbent for rapid removal of reactive dyes from the textile companies'wastewaters," Journal of the Iranian Chemical Society, vol. 7, no. 1, pp. S130-S144, 2010.

[27] X. Zhao, Y. Shi, Y. Cai, and S. Mou, "Cetyltrimethylammonium bromide-coated magnetic nanoparticles for the preconcentration of phenolic compounds from environmental water samples," Environmental Science and Technology, vol. 42, no. 4, pp. 1201-1206, 2008.

[28] A. L. Ahmad, S. W. Puasa, and M. M. D. Zulkali, "Micellarenhanced ultrafiltration for removal of reactive dyes from an aqueous solution," Desalination, vol. 191, no. 1-3, pp. 153-161, 2006.

[29] S. R. Jadhav, N. Verma, A. Sharma, and P. K. Bhattacharya, "Flux and retention analysis during micellar enchanced ultrafiltration for the removal of phenol and aniline," Separation and Purification Technology, vol. 24, no. 3, pp. 541-557, 2001.

[30] A. Mohammadi, Y. Yamini, and N. Alizadeh, "Dodecylsulfatedoped polypyrrole film prepared by electrochemical fiber coating technique for headspace solid-phase microextraction of polycyclic aromatic hydrocarbons," Journal of Chromatography A, vol. 1063, no. 1-2, pp. 1-8, 2005. 

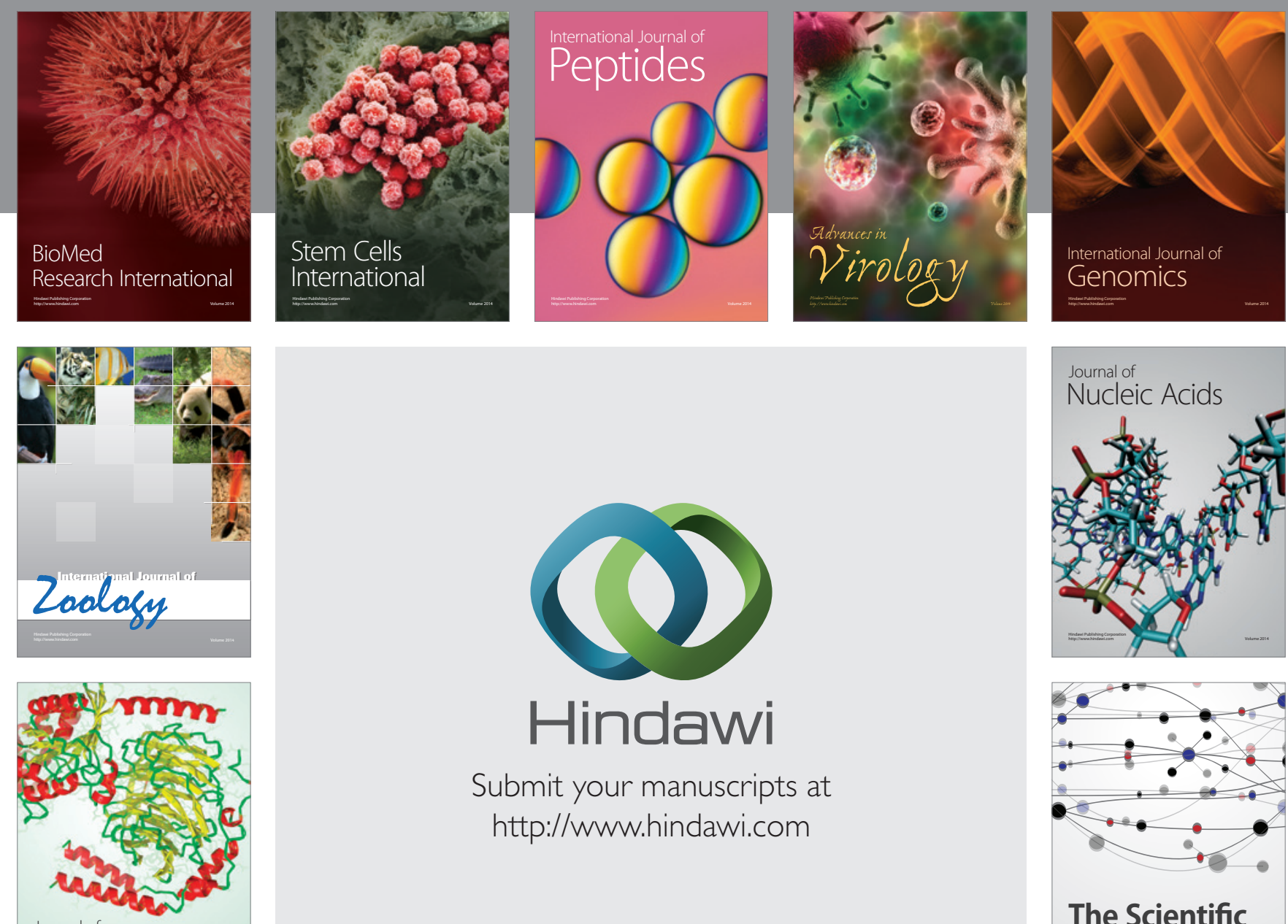

Submit your manuscripts at

http://www.hindawi.com

Journal of
Signal Transduction
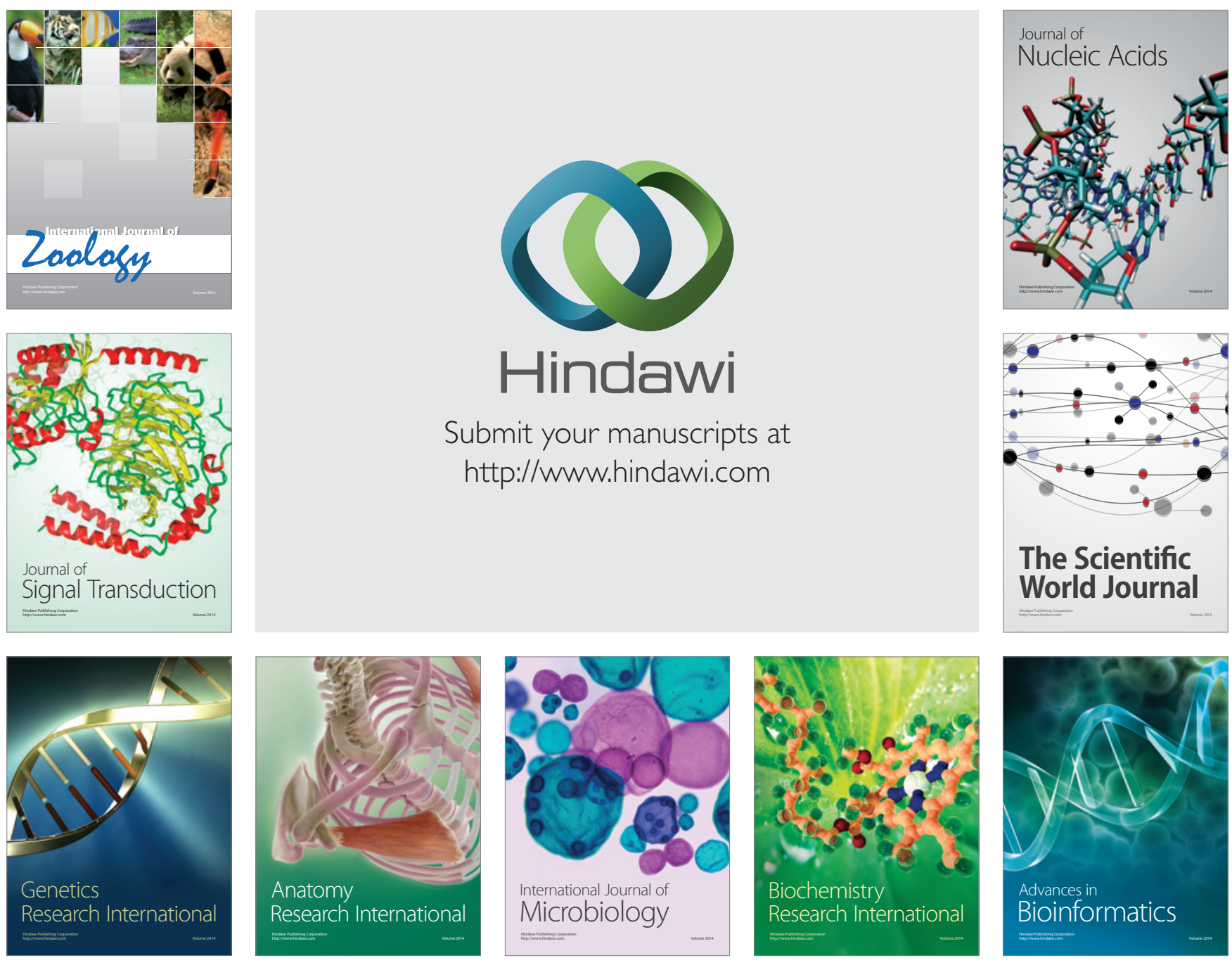

The Scientific World Journal
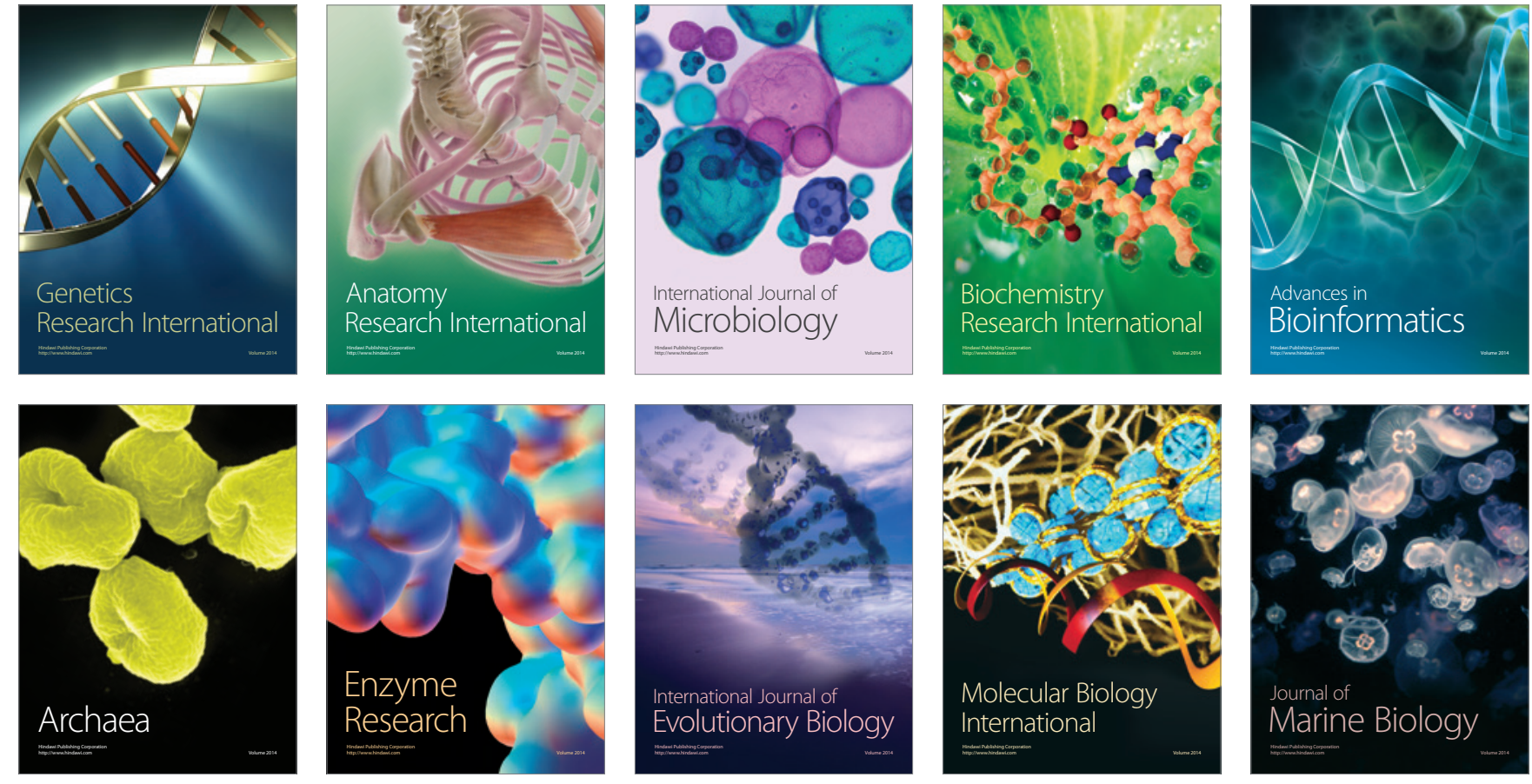